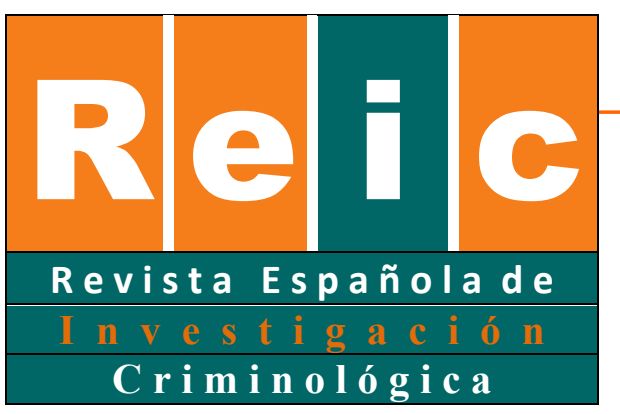

Martí \& Larrauri

\title{
Una defensa de la clasificación inicial de las penas cortas en régimen abierto
}

\section{Short Prison Sentences and Open Prisons}

\author{
Marta Martí ${ }^{1}$ iD \\ Universitat Oberta de Catalunya
}

\author{
Elena Larrauri iD \\ Universitat Pompeu Fabra
}

\section{RESUMEN}

El objetivo de este artículo es proporcionar argumentos para incrementar la aplicación del régimen penitenciario abierto. El artículo parte de que no solo la pena de prisión debe ser ultima ratio, sino que además la clasificación en régimen ordinario debe limitarse a las penas más graves. Se constata que una cantidad importante de penas cortas inferiores a 5 años tienen dificultades tanto para ser clasificadas inicialmente en tercer grado como para progresar de grado, por lo que paradójicamente las condenas más leves acaban cumpliéndose en su totalidad en prisiones cerradas. Con base en estos datos empíricos, formulamos dos propuestas normativas. En primer lugar, se sugiere que las penas inferiores a 5 años se clasifiquen de forman inicial en tercer grado y, por lo tanto, accedan al régimen abierto desde el comienzo de la condena. En segundo lugar, y de forma alternativa, se propone que el proceso de clasificación inicial se realice en las prisiones abiertas, esto es, en los centros abiertos y centros de inserción social. Este artículo defiende así que el régimen "ordinario" debe ser la ultima ratio respecto de las condenas que se ejecutan en prisión.

Palabras clave: prisiones abiertas, tercer grado, clasificación de grado, condenas cortas.

\footnotetext{
${ }^{1}$ La correspondencia debe dirigirse a: Grupo de Investigación en Criminología y Sistema Penal. Departamento de Derecho, Universitat Pompeu Fabra. C/ Ramon Trias Fargas. 25-27, 08005 Barcelona. Criminology.research@upf.edu.
}

Revista Española de Investigación Criminológica

Artículo 4, Número 18 (2020)

https://doi.org/10.46381/reic.v18i0.387

www.criminologia.net

ISSN: 1696-9219 


\begin{abstract}
The aim of this article is to provide arguments in order to increase the use of open prisons and reduce the application of closed prisons. This article considers that the severity of closed prisons should be limited to the most serious cases. We show that a significant number of sentences up to 5 years have difficulties both in being classified in open prisons from the beginning of the sentence, and in progressing and being transferred to them after having served some time in closed prisons. Paradoxically then the less serious offences end up serving all their sentence in a closed prison. Based on these empirical data, we suggest two proposals: first, we argue that sentences up to 5 years should be served in open prisons from the beginning of the sentence, and second, and alternatively, we propose that the categorisation process should be carried out in open prisons, instead of closed prisons. In short, we argue that closed prisons should be considered an ultima ratio way of serving a prison sentence.
\end{abstract}

Keywords: open prisons, minimum-security prisons, prisoners' categorization, short sentences.

\title{
1. Introducción
}

En el sistema penitenciario español el régimen ordinario representa estar encerrado en una cárcel las veinticuatro horas del día con la posibilidad de recibir una visita semanal de cuarenta minutos y, en el mejor de los casos, generalmente hacia el final de la condena, un permiso de salida una vez al mes (Rovira, Larrauri \& Alarcón, 2018). Nunca debería haberse llamado régimen "ordinario" a un régimen en el que la persona está encerrada todo el día ${ }^{2}$. Por ello, García Valdés (1989, p. 297) afirmó que el régimen abierto debía ser el régimen normal de cumplimiento, pudiéndose extender al 45\% de la población presa, y la propia Administración penitenciaria llegó a mencionar cuotas de hasta un 50\% (García Mateos, 2003, p. 111). En esta línea, sugerimos que el régimen abierto es el más adecuado para las penas leves y proponemos reservar la severidad del régimen ordinario a las penas graves ${ }^{3}$.

\footnotetext{
${ }^{2}$ En España el primer grado consiste esencialmente en un régimen de vida en aislamiento durante 20 horas; el segundo grado consiste en un "régimen de vida ordinario" que se cumple en una prisión cerrada; y el tercer grado es el que permite alcanzar un régimen de vida abierto, en semilibertad (a cumplir generalmente en un centro abierto). Por ello a lo largo del artículo enfatizaremos que el "régimen ordinario" se cumple en una prisión cerrada, esto es, la persona está todo el día en la cárcel.

${ }^{3}$ En este artículo consideramos penas graves aquellas superiores a cinco años y, en consecuencia, penas leves o "cortas", las inferiores a cinco años. Véase también esta idea en López (2004).

Revista Española de Investigación Criminológica

Artículo 4, Número 18 (2020)

https://doi.org/10.46381/reic.v18i0.387

www.criminologia.net

ISSN: 1696-9219
} 
Estar en un régimen abierto no equivale a dejar de cumplir una pena de prisión. Como ha sido puesto de relieve en diversas investigaciones (ampliamente, Martí, 2019b), a pesar de que en ocasiones la persona tiene un contacto limitado con el centro penitenciario y acude al mismo solo para dormir, los presos en régimen abierto generalmente tienen la obligación de trabajar o realizar un curso de formación, participar en un programa de tratamiento, no consumir alcohol ni otras drogas, y respetar la normativa del centro cuando se encuentran en él. Estas obligaciones y restricciones son supervisadas por los equipos técnicos y las Juntas de Tratamiento, siempre bajo la amenaza de ser regresados a segundo grado si no cumplen con lo establecido en su programa.

Como es conocido, al régimen abierto se accede mayoritariamente mediante la clasificación en tercer grado penitenciario, desde el inicio de la condena (clasificación inicial) o por progresión (progresión de grado). En España solo el 16,8\% de las personas presas están clasificadas en tercer grado, mientras que el restante $81,3 \%$ se encuentran en régimen ordinario $^{4}$-ya sea en segundo grado $(74,4 \%)$ o a la espera de clasificación $(6,9 \%)^{5}$. Además, la mayoría de los presos que acceden al tercer grado lo hacen por progresión, lo cual significa que han cumplido una parte de la condena en una prisión cerrada.

El objetivo de este artículo es proporcionar argumentos que favorezcan el aumento de la aplicación del régimen abierto. Para conseguirlo se sugieren dos propuestas: en primer lugar, que las penas cortas (inferiores a 5 años) se clasifiquen directamente en tercer grado $\mathrm{y}$, por lo tanto, accedan al régimen abierto desde el inicio de la condena; $\mathrm{y}$, en segundo lugar, y de forma alternativa, que el proceso de clasificación inicial se realice en las prisiones abiertas, esto es, en los centros de inserción social (CIS) en el ámbito de la Administración General del Estado (AGE) y en los centros abiertos en Cataluña.

\footnotetext{
${ }^{4}$ Porcentajes calculado a partir de los datos de la Secretaría General de Instituciones Penitenciarias (Ministerio del Interior) a diciembre de 2019. Además, existe un 1,9\% de presos clasificados en primer grado, lo que significa que están en un régimen de vida en aislamiento.

${ }^{5}$ Las personas en espera de clasificación se encuentran en prisiones cerradas con un régimen ordinario similar al de aquellas que están clasificadas en segundo grado. Es importante realzar que en este grupo están sobrerrepresentadas precisamente las personas con condenas muy cortas.
} 
Estas propuestas se basan en el análisis de los datos que expondremos a continuación ${ }^{6}$, que muestran las dificultades de acceso al régimen abierto de las penas cortas. Adicionalmente, se sustentan en la investigación empírica realizada por una de las autoras ${ }^{7}$, que permite concluir que el régimen abierto tiene capacidad de supervisar y controlar, esto es, tiene capacidad punitiva, y que así es también vivido por los penados (Martí, 2018; 2019b).

Entendemos que el régimen abierto es susceptible de ser ampliado por políticas penitenciarias como las propuestas, lo cual parece evidente solo con comparar las cifras de la AGE con las de Cataluña ${ }^{8}$ : mientras en la primera el porcentaje de personas presas en tercer grado es del $15,6 \%$, en la segunda llega al $24,5 \%{ }^{9}$.

A continuación, explicamos el proceso de clasificación y los criterios para acceder al tercer grado penitenciario, que como hemos mencionado es el requisito para cumplir la condena en semilibertad. Seguidamente, analizamos la forma mediante la cual una persona puede llegar al régimen abierto, ya sea desde el inicio de la condena o por progresión, prestando especial atención a la variable de la duración de la condena; y concluimos con la defensa de nuestras dos propuestas.

\footnotetext{
${ }^{6}$ En concreto, se han analizado datos sobre la clasificación en tercer grado proporcionados por el Servei de Classificació de la Secretaria de Mesures Penals, Reinserció i Atenció a la Víctima (SMPRAV) de Cataluña, y datos de fuentes secundarias como SPACE I del Consejo de Europa, los informes anuales de la Secretaría General de Instituciones Penitenciarias, datos disponibles en el Portal estadístico de la SMPRAV, datos abiertos del Centre d'Estudis Jurídics i Formació Especialitzada del Departament de Justícia de Catalunya, y otras investigaciones criminológicas.

${ }^{7}$ En el marco de esta investigación, entre los años 2017 y 2018, se llevaron a cabo 13 entrevistas a profesionales de tres centros abiertos de Cataluña y 18 entrevistas a personas que cumplían la condena en semilibertad (Martí, 2018).

${ }^{8} \mathrm{Y}$ ha puesto también de relieve la crisis del coronavirus, a raíz de la cual el Ministerio del Interior concedió la posibilidad de cumplir la semilibertad mediante control telemático a 2.100 personas, duplicando la cantidad de presos con estas medidas en el ámbito de la AGE en tan solo siete días (López-Fonseca, 2020, 18 de marzo).

${ }^{9}$ Porcentaje calculado a partir de los datos de la Secretaría General de Instituciones Penitenciarias (Ministerio del Interior) a diciembre de 2019.
}

Revista Española de Investigación Criminológica

Artículo 4, Número 18 (2020)

https://doi.org/10.46381/reic.v18i0.387

www.criminologia.net

ISSN: 1696-9219 


\section{La clasificación en tercer grado penitenciario}

El acceso al régimen abierto en España se produce en la mayoría de los casos mediante la clasificación en tercer grado penitenciario ${ }^{10}$. Esta clasificación corresponde a las Juntas de Tratamiento y debe ser aprobada por el Centro Directivo, esto es, la Dirección General de Ejecución Penal y Reinserción Social de la Secretaría General de Instituciones Penitenciarias (SGIP) en el territorio de la AGE y el Servei de Classificació de la Secretaria de Mesures Penals, Reinserció i Atenció a la Víctima (SMPRAV) en Cataluña.

En coherencia con el sistema de individualización científica, la clasificación en tercer grado puede acordarse en cualquier momento de la ejecución de la pena ${ }^{11}$, siendo posible tanto la clasificación en el inicio de la condena, conocida como clasificación inicial, como en un momento posterior, esto es, por progresión de grado.

En la práctica, las personas presas ingresan en los centros penitenciarios cerrados y son las Juntas de Tratamiento de estas prisiones las que realizan la propuesta de clasificación inicial. En los casos en los que se concede el tercer grado y se decide que este se va a cumplir en un CIS, en un centro abierto o en otro tipo de establecimiento de régimen abierto, se procede al traslado de la persona desde la prisión cerrada a la institución abierta.

\subsection{Criterios de clasificación}

La clasificación penitenciaria en el sistema español ${ }^{12}$ contempla una distinción entre requisitos generales y requisitos específicos (Tabla 1).

\footnotetext{
${ }^{10}$ También es posible cumplir la condena en régimen abierto estando clasificado en segundo grado mediante la aplicación del art. 100.2 del Reglamento Penitenciario, también denominado "principio de flexibilidad". Este artículo tiene carácter excepcional y permite adoptar un modelo de ejecución en el que pueden combinarse aspectos característicos de cada uno de los grados, siempre y cuando dicha medida se fundamente en un programa específico de tratamiento que de otra forma no pueda ser ejecutado. Es el equipo técnico el encargado de proponer a la Junta de Tratamiento la aplicación de este principio, que debe ser aprobada posteriormente por el Juzgado de Vigilancia Penitenciaria correspondiente (para más información, véanse Fernández Arévalo \& Nistal, 2011; Juanatey, 2016).

${ }^{11}$ Véanse más adelante los requisitos específicos.

${ }^{12}$ Para un análisis crítico de la normativa penitenciaria en materia de la clasificación de grados, véase Cutiño (2015c).
}

Revista Española de Investigación Criminológica

Artículo 4, Número 18 (2020)

https://doi.org/10.46381/reic.v18i0.387

www.criminologia.net

ISSN: 1696-9219 


\section{Tabla 1.}

Requisitos de acceso al tercer grado penitenciario

\begin{tabular}{|c|c|}
\hline Requisito general & Requisitos específicos \\
\hline $\begin{array}{l}\text { Capacidad de vivir en semilibertad, valorada en } \\
\text { función de las circunstancias personales y } \\
\text { penitenciarias }\left(\operatorname{art.} 102.4 \mathrm{RP}^{13}\right) \text {, detalladas en los } \\
\quad \text { arts. } 63 \mathrm{LOGP}^{14} \text { y } 102.2 \mathrm{RP} \text { : } \\
* \quad \text { La personalidad } \\
* \quad \text { El historial individual, familiar, social y } \\
\text { delictivo } \\
* \quad \text { La duración de las penas } \\
* \quad \text { El medio social al que retorne } \\
* \quad \text { Los recursos, facilidades y dificultades para el } \\
\text { buen éxito del tratamiento }\end{array}$ & $\begin{array}{l}\text { a) No estar bajo el periodo de seguridad (art. } \\
36.2 \text { Código Penal) } \\
\text { b) Haber satisfecho la responsabilidad civil (art. } \\
72.5 \text { LOGP) } \\
\text { c) [Delitos de terrorismo y organizaciones } \\
\text { criminales] Abandono de los fines y medios } \\
\text { terroristas y colaboración activa con las } \\
\text { autoridades (art. } 72.6 \text { LOGP) }\end{array}$ \\
\hline
\end{tabular}

Fuente: Elaboración propia a partir de la LOGP y el RP.

En cuanto al requisito general, el art. 102.4 RP dispone que se clasificarán en tercer grado aquellas personas que tengan "capacidad para llevar a cabo un régimen de vida en semilibertad"15. Este criterio general debe valorarse en función de las circunstancias personales y penitenciarias, detalladas en los arts. 63 LOGP y $102.2 \mathrm{RP}$, los cuales indican que para determinar la clasificación

se ponderarán la personalidad y el historial individual, familiar, social y delictivo del interno, la duración de la pena y medidas penales en su caso, el medio a que probablemente retornará y los recursos, facilidades y dificultades existentes en cada caso y momento para el buen éxito del tratamiento (art. 102.2 RP) ${ }^{16}$.

De este modo, se consideran tanto aspectos individuales, sociales, penales $\mathrm{y}$ penitenciarios como aspectos relacionados con el tratamiento (Mata, 2015), todos ellos

\footnotetext{
${ }^{13}$ Real Decreto 190/1996, de 9 de febrero, por el que se aprueba el Reglamento Penitenciario. «BOE», núm. 40, de 15 de febrero de 1996.

${ }^{14}$ Ley Orgánica 1/1979, de 26 de septiembre, General Penitenciaria. «BOE», núm. 239, de 5 de octubre de 1979.

${ }^{15}$ El régimen ordinario o segundo grado se define negativamente como la " $(\ldots)$ [no] capacidad para vivir, por el momento, en semilibertad" (art. 102.3 RP).

${ }^{16}$ Destaca Solar (2018) que en el Reglamento Penitenciario se observa una mayor importancia del enfoque social, y por ello la personalidad es solo uno de los elementos a valorar.
}

Revista Española de Investigación Criminológica

Artículo 4, Número 18 (2020)

https://doi.org/10.46381/reic.v18i0.387

www.criminologia.net

ISSN: 1696-9219 
aspectos valorativos - a excepción de la duración de la pena- y que deben ser considerados de manera global, sin que unos predominen sobre otros (Cervelló, 2005).

Dado lo genérico y la amplitud de las variables que conforman el marco legal anterior, las Administraciones penitenciarias han intentado concretar los criterios de acceso al tercer grado (es decir, cómo valorar la "capacidad para llevar a cabo un régimen de vida en semilibertad") y unificar los criterios de actuación de las distintas Juntas de Tratamiento.

En el caso de la AGE, la Instrucción SGIP 9/2007, de Clasificación y destino de penados, establece una serie de factores que los equipos técnicos y las Juntas de Tratamiento deben considerar para clasificar a una persona en tercer grado (véase Tabla I en el Anexo). Por ejemplo, la AGE valora positivamente la continuidad en el exterior en programas de tratamiento que ya venga realizando el interno, que exista la necesidad de realizar un tratamiento en el medio comunitario o que presente un proyecto de vida sólido y contrastable para hacer una "vida honrada" en libertad; además de criterios específicos, como haber disfrutado de permisos, tener un apoyo familiar pro social, asumir el delito, tener una personalidad responsable o carecer de sanciones disciplinarias.

Cataluña no tiene una Instrucción específica en la que se indiquen los criterios concretos para valorar la clasificación en tercer grado. Según Capdevila, Parés, Ferrer, Luque \& Torrecilla (2005, p. 16), en la mayoría de los supuestos se consideran "variables recogidas fruto de la experiencia”. En todo caso, la SMPRAV tiene la posibilidad de enviar indicaciones por vías internas, si bien esta información no es pública ${ }^{17}$.

Además del criterio general, la legislación penitenciaria española requiere cumplir con algunos requisitos específicos para acceder al tercer grado. El primero consiste en no estar en el periodo de seguridad (art. 36.2 Código Penal), el cual exige haber cumplido la mitad de la condena en segundo grado antes de acceder al tercer grado. El periodo de

\footnotetext{
${ }^{17}$ La SMPRAV (2011, p. 43) indica que para realizar la evaluación de los internos se emplean la escala de valoración del riesgo RisCanvi y otros instrumentos específicos; y para la evaluación de seguimiento o evolución se emplea el Sistema de Evaluación Continuada (SAM), regulado en la Circular 1/1999 sobre el sistema d'avaluació $i$ motivació continuada, la cual establece una serie de elementos que los equipos y Juntas de Tratamiento deben tener en cuenta para valorar la conducta de las personas en régimen ordinario y abierto de cara a una progresión.
}

Revista Española de Investigación Criminológica

Artículo 4, Número 18 (2020)

https://doi.org/10.46381/reic.v18i0.387

www.criminologia.net

ISSN: 1696-9219 
seguridad se aplica a condenas superiores a 5 años y, en la mayoría de los casos, se impone de forma facultativa por parte del juez sentenciador ${ }^{18}$.

El segundo requisito específico consiste en satisfacer la responsabilidad civil derivada del delito (art. 72.5 LOGP) $^{19}$. En la práctica no se suele exigir que se haya pagado efectivamente la totalidad de la responsabilidad civil antes de acceder al tercer grado, sino que se tiende a valorar que se haya abonado una parte de esta y el compromiso de continuar o iniciar el pago cuando la persona esté en régimen abierto. Ahora bien, como señala Solar (2009), el criterio es bastante abierto, por lo que la valoración depende en últimas de la Junta de Tratamiento de cada centro y de la postura más o menos restrictiva del Juzgado de Vigilancia Penitenciaria (JVP, en adelante) y el Ministerio Fiscal de cada circunscripción.

Asimismo, en los delitos de terrorismo o cometidos en el seno de organizaciones criminales se debe cumplir un tercer requisito específico: mostrar signos inequívocos de haber abandonado los fines y los medios terroristas, y colaborar activamente con las autoridades (art. 72.6 LOGP). Esta circunstancia puede acreditarse mediante una declaración expresa de repudio de sus actividades delictivas y de abandono de la violencia y una petición expresa de perdón a las víctimas de su delito, así como por los informes técnicos que acrediten que la persona está desvinculada de la organización terrorista y del entorno y actividades de asociaciones y colectivos ilegales que la rodean y su colaboración con las autoridades $^{20}$.

En resumen, los criterios de clasificación en tercer grado, requisito previo para disfrutar del régimen abierto, presentan la vaguedad característica de la legislación penitenciaria. Ello ocasiona una amplísima discrecionalidad por parte de las Juntas de

\footnotetext{
${ }^{18}$ El periodo de seguridad fue introducido por la reforma del Código Penal mediante la Ley 7/2003, de 30 de junio, de Medidas de reforma para el cumplimiento íntegro y efectivo de las penas. A pesar de que es una potestad de los jueces, existen una serie de supuestos considerados de especial gravedad en los que este periodo se aplica de forma automática siempre y cuando la condena sea superior a los 5 años. Es el caso, por ejemplo, de los delitos cometidos en el seno de una organización o grupo criminal o los delitos de abusos y agresiones sexuales a menores de 16 años.

${ }^{19}$ También introducido por la reforma del Código Penal mediante la Ley 7/2003, de 30 de junio, de Medidas de reforma para el cumplimiento íntegro y efectivo de las penas.

${ }^{20}$ Para más información sobre el caso específico de los delitos de terrorismo o cometidos en el seno de organizaciones criminales véanse Faraldo (2014), Fuentes (2011), Garro (2017) y Landa (2017).
}

Revista Española de Investigación Criminológica

Artículo 4, Número 18 (2020)

https://doi.org/10.46381/reic.v18i0.387

www.criminologia.net

ISSN: 1696-9219 
Tratamiento y la Administración penitenciaria ${ }^{21}$. Esta amplia discrecionalidad puede permitir que tanto la clasificación al régimen abierto, como los permisos, funcionen como motivación al cambio y/o forma de conseguir el orden interior. Sin embargo, es posible también que los criterios y los procedimientos utilizados sean cuestionados por su vaguedad y se ponga en duda la legitimidad de las decisiones. Y ello, paradójicamente, quizás disminuye en últimas tanto la motivación al cambio como el orden (Larrauri, 2020).

Además, como veremos a continuación, en la práctica, la masificación existente en los centros penitenciarios no permite una evaluación individualizada, y los factores que se tienen en cuenta, en opinión de diversos autores (Gallego, Cabrera, Ríos \& Segovia, 2010; Ríos \& Cabrera, 1998, 2002), son fundamentalmente los criterios penales de la duración de la condena y el tipo de delito. No obstante, dado que el 81,3\% de los presos están bajo un régimen ordinario ${ }^{22}$, ni siquiera la duración de la condena o el delito pueden explicar a nuestro juicio el automatismo de enviar y mantener a una amplia mayoría en una prisión cerrada.

\subsection{Procedimiento de clasificación en grado}

Con respecto al procedimiento de clasificación inicial, la Junta de Tratamiento es el órgano encargado de formular esta primera propuesta, que debe efectuarse "previo estudio del interno" (art. 103.1 RP). Durante este periodo previo de observación, que tiene lugar en un centro penitenciario cerrado, se debe recoger información para la valoración de los datos necesarios relacionados con los requisitos expuestos en el apartado anterior (posibilidad de tener un trabajo, conducta penitenciaria, entorno al que retornará la persona, y satisfacción de la responsabilidad civil, entre otros).

Respecto al tiempo previsto para realizar el estudio, el RP no exige un criterio mínimo temporal específico y dispone que para que una persona pueda ser propuesta para el tercer

\footnotetext{
${ }^{21}$ La valoración que realiza la Administración Central (el Centro Directivo) puede confirmar o no las peticiones de las Juntas de Tratamiento, si bien no existen investigaciones empíricas que indiquen en qué casos se separa del acuerdo de las Juntas y por qué motivos.

${ }^{22}$ En concreto, como se ha señalado, el 1,9\% está en primer grado, el $74,4 \%$ en segundo grado, y el $6,9 \%$ en espera de clasificación (véanse notas al pie de página número 5 y 6 ).
}

Revista Española de Investigación Criminológica

Artículo 4, Número 18 (2020)

https://doi.org/10.46381/reic.v18i0.387

www.criminologia.net

ISSN: 1696-9219 
grado "deberá transcurrir el tiempo de estudio suficiente para obtener un adecuado conocimiento del mismo y concurrir favorablemente calificadas las variables intervinientes en el proceso de clasificación penitenciaria enumeradas en el art. 102.2, valorándose, especialmente, el historial delictivo y la integración social del penado" (art. 104.3 RP) ${ }^{23}$. En todo caso, la propuesta debe formularse en el plazo máximo de dos meses, a contar desde la recepción del testimonio de sentencia (art. 103.2 RP), aunque es posible ampliarlo hasta un máximo de dos meses más (art. 103.6 RP).

Cabe destacar que varias investigaciones españolas cuestionan que los plazos previstos se estén cumpliendo, teniendo en cuenta la sobresaturación del sistema penitenciario (Cabrera \& Ríos, 1998, 2002; Cutiño, 2015a; Gallego et al., 2010). Además, como hemos comentado, en la práctica, la masificación existente en los centros penitenciarios no siempre permite una evaluación individualizada y esta actividad tiende a reducirse a la recogida de datos tasados en un formulario tipo.

El órgano competente para dictar la resolución de clasificación presenta diferencias en función de si se trata de condenas superiores o inferiores a un año. En el caso de las penas de prisión superiores a 1 año, el órgano competente para resolver la propuesta de clasificación es la Junta de Tratamiento, y debe ser aprobada por el Centro Directivo ${ }^{24}$. Por el contrario, en el caso de las penas de prisión de hasta 1 año, cuando la propuesta de clasificación dictada por la Junta de Tratamiento es adoptada de forma unánime por todos los miembros, esta tiene la consideración de clasificación inicial a todos los efectos (art. 103.7 RP), conociéndose esta modalidad como "clasificación ejecutiva" 25 .

La resolución de la clasificación inicial se debe notificar a la persona presa, quien puede recurrir la decisión ante el JVP (art. 103.5 RP). Asimismo, todas las resoluciones de clasificación (y progresión) a tercer grado se deben notificar al Ministerio Fiscal. Si la

\footnotetext{
${ }^{23}$ Como es conocido, la clasificación en tercer grado puede ser desde el inicio y no requiere, como sí sucede respecto de los permisos, que tenga extinguida la cuarta parte de la condena.

${ }^{24}$ Recordemos que en Cataluña el Centro Directivo es el Servei de Classificació de la Secretaria de Mesures Penals, Reinserció i Atenció a la Víctima (SMPRAV) y en la AGE es la Dirección General de Ejecución Penal y Reinserción Social de la SGIP.

${ }^{25} \mathrm{Si}$ la propuesta no es adoptada de forma unánime, se remite al Centro Directivo para que dicte resolución de clasificación inicial (art. 103.9 RP).
} 
persona presa o el Ministerio Fiscal no interponen recurso ante el JVP, este no puede intervenir de oficio; hecho muy criticado por parte de la doctrina (entre otros, Cervelló, 2012; Leganés, 2013; Torrecilla, 2009) y los propios jueces (Leganés, 2013), quienes consideran que las clasificaciones a tercer grado deberían como mínimo notificarse a los Jueces, respetando así la judicialización de la ejecución de las penas prevista por la Constitución española (art. 117.3).

En el caso que se considere que una persona no cumple con los requisitos para acceder inicialmente al tercer grado, se la clasifica en primer o segundo grado, de manera que debe permanecer en una prisión cerrada a la espera de que se realice una revisión de grado de oficio al cabo de seis meses ${ }^{26}$. De este modo, en función del procedimiento de acceso al régimen abierto es posible identificar dos grupos de personas presas: el que es clasificado en tercer grado desde el inicio de la condena y un segundo grupo que llega por progresión tras haber cumplido una parte de la pena en segundo grado.

A continuación vamos a examinar con mayor detalle las características de los dos tipos de personas presas que acceden al régimen abierto, esto es, aquellas que lo alcanzan en la clasificación inicial y aquellas que lo hacen por progresión, prestando especial atención a la duración de la pena, por la importancia que tiene esta variable en la clasificación.

\section{Clasificación inicial en régimen abierto}

Como ya hemos expuesto, la clasificación en régimen abierto es una decisión administrativa susceptible de ser ampliada por una decisión de política penitenciaria, lo que puede observarse, por ejemplo, al comparar las cifras de la AGE, que tiene solo un 15,6\% de presos en tercer grado, con las de la Administración de Cataluña, cuyo porcentaje es del $24,5 \%{ }^{27}$.

\footnotetext{
${ }^{26}$ El procedimiento de la revisión de grado se inicia con la presentación del informe sobre la evolución del penado a la Junta de Tratamiento por parte del equipo técnico. La Junta de Tratamiento debe formular su propuesta de mantenimiento de grado, progresión o regresión reconsiderando, en su caso, todos los aspectos que se establecieron en el modelo individualizado de tratamiento inicial (arts. 65.4 LOGP y 105.1 RP) y la remite al Centro Directivo, que debe resolver la propuesta siguiendo las mismas formalidades y plazos que los previstos para la clasificación inicial (art. 106.5 RP).

${ }^{27}$ Porcentaje calculado a partir de los datos de la Secretaría General de Instituciones Penitenciarias (Ministerio del Interior) a diciembre de 2019.
}

Revista Española de Investigación Criminológica

Artículo 4, Número 18 (2020)

https://doi.org/10.46381/reic.v18i0.387

www.criminologia.net

ISSN: $1696-9219$ 
El estudio de los datos de la SGIP y la SMPRAV muestran que, a lo largo del año 2018, se realizaron en España un total de 12.066 clasificaciones en tercer grado, de las cuales solo el 34\% fueron clasificaciones iniciales y el 66\% progresiones de grado (Tabla 2). No obstante, si observamos estos datos en función de la Administración, es posible advertir importantes diferencias, ya que en la AGE las clasificaciones iniciales supusieron un 31,7\% de las clasificaciones en tercer grado, mientras que en Cataluña llegaron a ser el 45,1\%.

\section{Tabla 2.}

Clasificaciones en tercer grado según la forma de acceso durante el 2018

\begin{tabular}{lccccc}
\hline & Clasificación inicial & \multicolumn{3}{c}{ Progresión de grado } & Total \\
\hline & $\mathrm{N}$ & $\%$ & $\mathrm{~N}$ & $\%$ & \\
\hline AGE & 3.145 & $31,7 \%$ & 6.790 & $68,3 \%$ & 9.935 \\
CAT & 962 & $45,1 \%$ & 1.169 & $54,9 \%$ & 2.131 \\
Total & 4.107 & $34,0 \%$ & 7.959 & $66,0 \%$ & 12.066
\end{tabular}

Fuente: Elaboración propia. Los datos relativos a la AGE se han extraído del Informe anual del 2018 (SGIP, 2019). Los datos sobre Cataluña se han obtenido de los Estadísticos descriptivos disponibles en el Portal estadístico de la SMPRAV.

En un estudio realizado en Cataluña por Capdevila et al. (2005, p. 68), en el que se analizan las diferencias entre el perfil de las personas que fueron clasificadas inicialmente en tercer grado con el de las clasificadas inicialmente en segundo grado ${ }^{28}$, se advierte que uno de los aspectos decisivos en la clasificación inicial es la duración de la condena, pues los datos muestran que las penas superiores a 5 años tienen muy pocas posibilidades de acceder el régimen abierto al inicio de la condena, especialmente si las comparamos con las condenas más cortas, que son las que reciben el tercer grado inicial en mayor medida.

\footnotetext{
${ }^{28}$ Para realizar el estudio, los autores tomaron una muestra de personas condenadas en el año 2001 clasificadas inicialmente en tercer grado y una muestra de personas también condenadas en el año 2001 pero clasificadas inicialmente en segundo grado (grupo de comparación), y llevaron a cabo un seguimiento penal y penitenciario de ambas muestras hasta el año 2005. Los datos utilizados son datos secundarios, obtenidos de la consulta de los expedientes informáticos de los internos en el SIPC (Sistema Informático Penitenciario Catalán) y de expedientes físicos de los internos que están archivados en el Centro Directivo de la Secretaría de Servicios Penitenciarios, Rehabilitación y Justicia Juvenil.
} 
En efecto, a medida que aumenta la duración de la condena, el porcentaje de clasificaciones iniciales en tercer grado disminuye, tal y como se muestra en la Tabla 3 con datos de la SMPRAV relativos al 2019. Así, en Cataluña solo el 4\% de las condenas de entre 5 y 10 años y el 1,4\% de las condenas de entre 10 y 15 años que fueron clasificadas por primera vez durante el 2019 recibieron el tercer grado de forma inicial. En cambio, el 50,7\% de las condenas inferiores a 2 años y el 28,1\% de las condenas de entre 2 y 5 años fueron clasificadas inicialmente en tercer grado.

\section{Tabla 3.}

Clasificación inicial según duración de la pena en Cataluña, $2019^{29}$

\begin{tabular}{|c|c|c|c|c|c|}
\hline \multirow[b]{2}{*}{ Hasta 2 años } & \multicolumn{2}{|c|}{$2^{\circ}$ grado inicial } & \multicolumn{2}{|c|}{ 3r grado inicial } & \multirow{2}{*}{$\begin{array}{l}\text { Total } \\
1.344\end{array}$} \\
\hline & 663 & $49,3 \%$ & 681 & $50,7 \%$ & \\
\hline Hasta 6 meses & 219 & $39,8 \%$ & 331 & $60,2 \%$ & 550 \\
\hline 6 meses- 1 año & 171 & $47,1 \%$ & 192 & $52,9 \%$ & 363 \\
\hline 1-2 años & 273 & $63,3 \%$ & 158 & $36,7 \%$ & 431 \\
\hline De 2 a 5 años & 512 & $71,9 \%$ & 200 & $28,1 \%$ & 712 \\
\hline 2-3 años & 195 & $69,6 \%$ & 85 & $30,4 \%$ & 280 \\
\hline 3-5 años & 317 & $73,4 \%$ & 115 & $26,6 \%$ & 432 \\
\hline De 5 a 10 años & 333 & $96,0 \%$ & 14 & $4,0 \%$ & 347 \\
\hline De 10 a 15 años & 69 & $98,6 \%$ & 1 & $1,4 \%$ & 70 \\
\hline Más de 15 años & 34 & $100,0 \%$ & 0 & $0,0 \%$ & 34 \\
\hline Total & 1.611 & $64,3 \%$ & 896 & $35,7 \%$ & 2.507 \\
\hline
\end{tabular}

Fuente: Elaboración propia. Datos facilitados por la SMPRAV mediante el Portal de Transparencia.

Sin embargo, el dato de la Tabla 3 que, a nuestro juicio, merece mayor reflexión es que el 49,3\% de las penas inferiores a 2 años y el 71,9\% de las penas de 2 a 5 años fueron inicialmente clasificadas en segundo grado. Así podemos ver que incluso las condenas más cortas a menudo reciben una clasificación inicial en un régimen "ordinario" (a cumplir en

\footnotetext{
${ }^{29}$ No se incluyen los casos en los que la persona fue clasificada en primer grado de forma inicial. Además, se han eliminado 159 casos respecto de los cuales no se tenía información sobre la duración de la condena. 
prisión cerrada), cuando sería defendible que, atendiendo a su poca gravedad, estas penas pudieran cumplirse desde el inicio en régimen abierto.

El estudio de Capdevila et al. (2005) muestra que, además de la duración de la condena, existen una serie de variables socioeconómicas que también influyen en la posibilidad de ser clasificado inicialmente en tercer grado. Así, ser extranjero, no tener apoyo familiar, no tener pareja, que la familia y/o la pareja tengan antecedentes delictivos, no tener una vivienda estable y no tener opción de tener un contrato laboral son factores que predominan en mayor medida entre aquellos que son clasificados inicialmente en segundo grado, mientras que aquellos que son clasificados en tercer grado presentan una situación más favorable en relación con estos factores (véase Tabla II en el Anexo). En consecuencia, es posible afirmar que el sistema de clasificación inicial, al considerar variables de tipo socioeconómico como obstáculos que dificultan el acceso al tercer grado, ${ }^{30}$ estaría precisamente castigando la exclusión social (Ríos \& Cabrera, 1998).

Por último, respecto a la clasificación inicial en tercer grado, cabe destacar además que algunos estudios muestran que una cantidad importante de las penas más cortas (inferiores a 1 año) quedan excluidas totalmente del acceso al tercer grado y en consecuencia del avance al régimen abierto en algún momento de la condena. El motivo fundamental es la falta de tiempo para realizar la clasificación antes de que finalice la pena (CEJFE, 2015, p. 113). Por ejemplo, el paso por prisión de las personas que entran por responsabilidad personal subsidiaria por impago de multa es muy breve -unos 39,59 días de media- y el 88,2\% de ellas salen de prisión sin haber recibido una clasificación de grado, por lo que cumplen la totalidad de la condena en una prisión cerrada (CEJFE, 2015, p. 116) ${ }^{31}$. El hecho paradójico de que las penas más cortas se cumplan de forma íntegra en una prisión cerrada nos parece criticable y

\footnotetext{
${ }^{30}$ Ver también Apartado 4 y Tabla 5.

${ }^{31}$ Estos casos de penas muy cortas que no llegan a recibir una clasificación no aparecen registrados en la anterior Tabla 3, ya que esta únicamente recoge datos sobre las personas que sí fueron clasificadas de forma inicial durante el 2019. Esto significa que el porcentaje de condenas cortas inferiores a 2 años que son clasificadas en tercer grado de forma inicial, en realidad, es menor al 50,7\% mencionado anteriormente. En concreto, el grupo más afectado sería el de las condenas muy cortas, de manera que el dato que se indica en la Tabla 3 relativo a que el $60,2 \%$ de las condenas inferiores a 6 meses se clasifican en tercer grado inicial está sobrerrepresentado porque no tiene en cuenta aquellos presos con este tipo de condenas que no reciben clasificación.
} 
aporta un argumento adicional en favor de clasificar las condenas cortas desde un inicio en régimen abierto.

\section{Clasificación por progresión: ¿Quién progresa?}

Algunas personas acceden al régimen abierto por progresión, tras haber cumplido una parte de la condena en segundo grado (y algunas también en primer grado). Como señalamos anteriormente, el 66\% de las personas que accedieron al tercer grado en 2018 en España lo hicieron mediante progresión de grado, siendo esta proporción mayor en la AGE que en Cataluña $(68,3 \% \text { y } 54,9 \% \text { respectivamente })^{32}$.

En consecuencia, es relevante preguntarse ¿qué características tienen las personas que progresan al régimen abierto en comparación con aquellas que no llegan a progresar?

De acuerdo con la investigación criminológica, una de las variables relacionadas significativamente con la posibilidad de acceder al régimen abierto es, de nuevo, la duración de la pena. Pedrosa (2019, p. 16) muestra que cuanto mayor duración tiene la condena, mayor probabilidad de finalizar de forma progresiva, es decir, de acceder al régimen abierto. Esto indicaría que si bien, como hemos visto anteriormente, las condenas más largas tienen menos posibilidades de acceder al tercer grado inicial, esta situación se invierte cuando se trata de progresar de grado en un momento posterior.

Así, el 74\% de las personas con una pena inferior a 2 años que finalizaron la condena en 2010 se encontraban en una prisión cerrada ${ }^{33}$. En cambio, entre las personas con una condena de entre 2 y 5 años, el mismo porcentaje fue del 43,2\%, y entre aquellas con condenas superiores a 5 años, del 39,9\% (Tabla 4). Estos datos indican que, en efecto, las penas más cortas son las que tienen más dificultades para finalizar la condena en régimen abierto.

\footnotetext{
${ }^{32}$ Además, existe una cantidad importante de personas que no llegan a progresar al régimen abierto y finalizan la condena en prisiones cerradas. De acuerdo con el estudio de Ibàñez \& Cid (2016, p. 15), el 63,2\% de las personas que finalizaron la condena en 2010 en Cataluña estaban clasificadas en primer o segundo grado y, por lo tanto, no tuvieron una transición progresiva a la comunidad.

${ }^{33}$ El 35,8\% estaba clasificado en primer o segundo grado, y el 38,1\% estaba sin clasificar.
}

Revista Española de Investigación Criminológica

Artículo 4, Número 18 (2020)

https://doi.org/10.46381/reic.v18i0.387

www.criminologia.net

ISSN: 1696-9219 
En otras palabras, las condenas más cortas presentan una situación ventajosa para ser clasificadas inicialmente en tercer grado, pero mayores dificultades para progresar si su clasificación inicial ha sido en segundo grado. De este modo, numerosas condenas cortas ${ }^{34}$ son cumplidas de forma íntegra en una prisión cerrada, no solo, como habíamos comentado, porque muchas de ellas no son clasificadas, sino también debido a que son clasificadas en primer o segundo grado y después no son progresadas ${ }^{35}$.

\section{Tabla 4.}

Grado de tratamiento en el momento de la excarcelación según duración de la condena en Cataluña, $2010^{36}$

\begin{tabular}{lrrrrrrrrrr}
\hline & \multicolumn{2}{c}{ Sin clasificar } & $\mathbf{1}^{\mathbf{0}} \mathbf{0} \mathbf{2}^{\mathbf{0}}$ grado & \multicolumn{2}{c}{ 3r grado } & \multicolumn{2}{c}{$\begin{array}{c}\text { Libertad } \\
\text { condicional }\end{array}$} & $\begin{array}{c}\text { Prisión } \\
\text { cerrada* }\end{array}$ & Total \\
\hline $\begin{array}{l}\text { Menos de 2 } \\
\text { años }\end{array}$ & 673 & $38,1 \%$ & 633 & $35,8 \%$ & 362 & $20,5 \%$ & 98 & $5,5 \%$ & $74,0 \%$ & 1.766 \\
\hline De 2 a 5 años & 9 & $0,9 \%$ & 407 & $42,3 \%$ & 176 & $18,3 \%$ & 371 & $38,5 \%$ & $43,2 \%$ & 963 \\
\hline Más de 5 años & 4 & $0,6 \%$ & 269 & $39,3 \%$ & 161 & $23,5 \%$ & 251 & $36,6 \%$ & $39,9 \%$ & 685 \\
\hline
\end{tabular}

* Suma de las categorías "sin clasificar" y $1^{\circ}$ y $2^{\circ}$ grado.

Fuente: Elaboración propia. Datos abiertos “Taxa de reincidència penitenciària 2014” disponibles en la página web del Centre d'Estudis Jurídics i Formació Especialitzada del Departament de Justícia de Catalunya.

Lógicamente, una de las explicaciones a la mayor dificultad de las condenas cortas para progresar a tercer grado ${ }^{37}$ está relacionada con la falta de tiempo para llevar a cabo la denominada "cadena permisiva". Algunos estudios muestran que para acordar la progresión a tercer grado el personal de tratamiento acostumbra a exigir que la persona haya disfrutado

\footnotetext{
${ }^{34}$ Por ejemplo, a lo largo del año 2010 en Cataluña al menos 684 personas cumplieron condenas cortas (generalmente de unos días o meses de duración) íntegramente en prisiones cerradas por responsabilidad personal subsidiaria por impago de multa (CEJFE, 2015, p. 116).

${ }^{35}$ Sin contabilizar las penas sin clasificar, el 57,9\% de las personas que finalizaron la condena en 2010 con una pena inferior a 2 años lo hizo estando en primer o segundo grado, mientras que entre las personas con una pena de 2 a 5 años este porcentaje es del 4,7\%, y entre aquellos con una pena superior a 5 años, del $39,5 \%$ (datos calculados a partir de la Tabla 4).

${ }^{36}$ Estos datos hacen referencia a personas presas que finalizaron su condena durante el año 2010 en una prisión catalana (ver CEJFE, 2015).

${ }^{37}$ Nos estamos refiriendo aquí a las condenas cortas respecto de las cuales se considera que deben recibir tratamiento en el medio cerrado y, por lo tanto, han sido clasificadas en segundo grado, y no a aquellas penas cortas que finalizan la condena antes de llegar a ser clasificadas, como los casos de penas por responsabilidad personal subsidiaria por impago de multa.
} 
de varios permisos de salida (CEJFE, 2014), y es posible que ello no suceda en las condenas cortas, sobre todo si tenemos en cuenta que la mayoría de los presos obtiene los permisos en la etapa final de su condena (Rovira et al., 2018).

Además, hay que tener en cuenta que nos estamos refiriendo a personas a las que, a pesar de tener una condena corta, no se las ha considerado idóneas para el tercer grado inicial y se las ha clasificado en segundo grado. En estos casos, muchos profesionales tienden a pensar que los presos presentan "necesidades" o "problemáticas" que se deben trabajar en el medio cerrado antes de poder empezar a disfrutar de permisos ${ }^{38}$. Sin embargo, debe recordarse que hay una cantidad insuficiente de programas de tratamiento, lo que puede conllevar que la persona deba esperar cierto tiempo para iniciar sus actividades tratamentales en el interior del centro penitenciario ${ }^{39}$.

Por último, queremos señalar que la valoración de la progresión de grado no solo tiene en cuenta la duración de la condena, sino que, como ya advertimos al explicar la clasificación inicial, toma en consideración otras variables de tipo socioeconómico. En la Tabla 5 se muestran aquellos aspectos que diversos estudios criminológicos han destacado como los obstáculos más importantes para la progresión a tercer grado. Como puede observarse, los factores socioeconómicos, entre los cuales se encuentra no tener un domicilio o no ser acogido por una institución, y no tener oportunidades claras de trabajo fuera de prisión, son relevantes. Además, también se consideran variables penales y penitenciarias, como el haber cometido infracciones disciplinarias o haber sido regresado de grado ${ }^{40}$.

\footnotetext{
${ }^{38}$ Según el estudio de CEJFE (2014), algunos profesionales del sistema penitenciario catalán afirman que el tratamiento que se lleva a cabo en el medio abierto no es suficiente o adecuado para tratar algunas problemáticas, y por ello son reticentes a clasificar en tercer grado las personas respecto de las cuales consideran que requieren un tratamiento más intenso. Esta reticencia quizás también se explica por las expectativas demasiado elevadas de algunos profesionales que aspiran a convertir al preso en "ciudadano virtuoso" (Larrauri, 2019).

${ }^{39}$ Por ejemplo, si se decide que alguien debe participar en un determinado programa de tratamiento y este ya ha empezado o no dispone de plazas suficientes, la persona deberá esperar hasta que se dé inicio de nuevo al programa, retrasando la posibilidad de empezar a disfrutar de permisos de salida.

${ }^{40}$ En opinión de Leganés (2013, p. 352) si bien la evaluación para la progresión debería versar sobre "las actitudes y formas de actuar estables indicativas de la pervivencia de cierta peligrosidad criminal", en la práctica tanto los equipos técnicos como los JVP suelen reducir la valoración de la evolución conductual del penado al ámbito de lo disciplinario. De acuerdo con Cutiño (2015a, p. 9), esto se explica porque la observación de la conducta se lleva a cabo por los funcionarios de vigilancia, quienes se dedican principalmente al control disciplinario y a la evitación de fugas, lo que implica que la evolución positiva en el tratamiento se entienda
}

Revista Española de Investigación Criminológica

Artículo 4, Número 18 (2020)

https://doi.org/10.46381/reic.v18i0.387

www.criminologia.net

ISSN: $1696-9219$ 


\section{Tabla 5.}

Recopilación de variables relacionadas con la progresión a tercer grado según los estudios criminológicos $^{41}$

\begin{tabular}{|c|c|}
\hline Variables socioeconómicas & Variables penales y penitenciarias \\
\hline $\begin{array}{l}\text { No tener un domicilio o no ser acogido por una } \\
\text { institución }\end{array}$ & No haber satisfecho la responsabilidad civil \\
\hline Tener una toxicomanía activa & Haber cometido infracciones disciplinarias \\
\hline $\begin{array}{l}\text { No tener oportunidades claras de trabajo fuera de } \\
\text { prisión }\end{array}$ & $\begin{array}{l}\text { No tener disposición para realizar cursos u otras } \\
\text { actividades programadas o programas de } \\
\text { desintoxicación }\end{array}$ \\
\hline Tener una falta de apoyo social externo & No haber disfrutado de permisos penitenciarios \\
\hline $\begin{array}{l}\text { Ser extranjero, especialmente en situación } \\
\text { administrativa irregular }\end{array}$ & Haber sido regresado de grado \\
\hline
\end{tabular}

Fuente: Elaboración propia.

\section{Propuestas}

Como ya comentamos en la introducción, el objetivo de este artículo es suministrar argumentos que favorezcan la clasificación en régimen abierto, y para ello concluimos con dos propuestas relacionadas: la clasificación inicial en régimen abierto de las penas de prisión inferiores a 5 años, y en segundo lugar y alternativamente, la posibilidad de clasificar a todas las personas penadas originariamente en los CIS o centros abiertos.

\subsection{La clasificación inicial proporcional}

La primera propuesta consiste en clasificar las condenas inferiores a 5 años inicialmente en tercer grado. Ello conllevaría prácticamente tener en torno a la mitad de la población presa en régimen abierto. Así, como puede verse en la Tabla 6, en Cataluña el 44,5\% de las

generalmente como sinónimo de carecer de sanciones disciplinarias, "operándose una confusión entre los objetivos del régimen y los fines del tratamiento".

${ }^{41}$ Algunos estudios relevantes sobre el acceso y la progresión a tercer grado en España son CEJFE (2014), Cid \& Tébar (2013), Cutiño (2015b), Ibàñez (2019), Ibàñez \& Cid (2016), y Pedrosa (2019).

Revista Española de Investigación Criminológica

Artículo 4, Número 18 (2020)

https://doi.org/10.46381/reic.v18i0.387

www.criminologia.net

ISSN: 1696-9219 
personas presas tienen condenas inferiores a los 5 años y en la AGE el porcentaje es del $50,1 \%$.

Tabla 6.

Personas presas según duración de la condena (enero 2018)

\begin{tabular}{lrrrrrr}
\hline & \multicolumn{2}{c}{ Cataluña } & \multicolumn{2}{c}{ AGE } & \multicolumn{2}{c}{ TOTAL } \\
& \multicolumn{1}{c}{$\mathbf{N}$} & \multicolumn{1}{c}{$\boldsymbol{r}$} & \multicolumn{1}{c}{$\mathbf{N}$} & \multicolumn{1}{c}{$\%$} & \multicolumn{1}{c}{ N } & \multicolumn{1}{c}{$\%$} \\
\hline Hasta 3 años & 1.683 & $23,5 \%$ & 12.973 & $30,0 \%$ & 14.656 & $29,0 \%$ \\
\multicolumn{1}{c}{ Hasta 6 meses } & 173 & $2,4 \%$ & 1.678 & $3,9 \%$ & 1.851 & $3,7 \%$ \\
6 meses-1 año & 333 & $4,6 \%$ & 2.636 & $6,1 \%$ & 2.969 & $5,9 \%$ \\
\multicolumn{1}{c}{$1-3$ años } & 1.177 & $16,4 \%$ & 8.659 & $20,0 \%$ & 9.836 & $19,5 \%$ \\
\hline De 3 a 5 años & 1.512 & $21,1 \%$ & 9.132 & $21,1 \%$ & 10.644 & $21,1 \%$ \\
\hline 5-10 años & 2.174 & $30,4 \%$ & 11.518 & $26,6 \%$ & 13.692 & $27,1 \%$ \\
\hline 10-20 años & 1.487 & $20,8 \%$ & 7.720 & $17,8 \%$ & 9.207 & $18,2 \%$ \\
\hline más de 20 años & 307 & $4,3 \%$ & 1.971 & $4,6 \%$ & 2.278 & $4,5 \%$ \\
\hline Total & 7.163 & $100 \%$ & 43.314 & $100 \%$ & 50.477 & $100 \%$ \\
\hline
\end{tabular}

Fuente: Elaboración propia. Datos de SPACE I del Consejo de Europa.

El argumento principal que sustenta la posibilidad de clasificar automáticamente estas penas en tercer grado es que se trata de delitos poco graves; incluso una parte importante de estas penas de prisión son susceptibles de ser suspendidas por los Juzgados de Ejecución ${ }^{43}$.

En segundo lugar, la clasificación inicial de las penas cortas en régimen abierto se justifica también por la evidencia presentada (véase Tabla 4) de que las personas con condenas cortas de prisión a menudo las cumplen en su totalidad en régimen "ordinario" (es decir, en prisión cerrada) porque no llegan a ser clasificadas o bien porque son clasificadas en segundo grado y luego no son progresadas.

Por último, esta propuesta puede ser reforzada con las teorías de la pena (Peñaranda, 2019). Así, de acuerdo con la "teoría del merecimiento", podría argüirse que entrar en una prisión cerrada por un delito poco grave es desproporcional. También desde la finalidad de

${ }^{42}$ En concreto, Cataluña tiene un $23,5 \%$ de penas inferiores a 3 años y un $21,1 \%$ de penas de 3 a 5 años. La AGE tiene un $29 \%$ de penas inferiores a 3 años y un $21,1 \%$ de 3 a 5 años.

${ }^{43}$ Véase el reciente estudio de Varona (2019).

Revista Española de Investigación Criminológica

Artículo 4, Número 18 (2020)

https://doi.org/10.46381/reic.v18i0.387

www.criminologia.net

ISSN: 1696-9219 
la reinserción es criticable, pues esta se dificulta si la persona entra en una prisión cerrada, ya que, aun cuando el periodo de condena sea "corto", los efectos del encarcelamiento pueden dificultar el posterior proceso de reinserción ${ }^{44}$.

En contra de que las condenas cortas se cumplan en régimen abierto desde el inicio de la condena se esgrimen dos argumentos principales. El primero alude a que empezar una pena de prisión en régimen abierto vacía de contenido la condena ${ }^{45}$. Esta posición suele asumir que el cumplimiento en un centro abierto no es compatible con el cumplimiento íntegro y efectivo de la pena (Fuentes, 2011).

Ante esta concepción puede argumentarse que los presos en régimen abierto, especialmente aquellos que se encuentran en prisiones abiertas como los CIS y los centros abiertos, siguen teniendo una serie de obligaciones, tanto de carácter rehabilitador como de control. Estar en un régimen abierto no equivale a dejar de cumplir una pena de prisión, pues a pesar de que en ocasiones la persona tiene un contacto limitado con el centro penitenciario y acude al mismo solo para dormir, se le pueden imponer, y se le imponen, otros tipos de obligaciones y restricciones que son supervisadas por los equipos técnicos y las Juntas de Tratamiento. Así, los presos en régimen abierto suelen tener la obligación de trabajar o realizar un curso de formación, participar en un programa de tratamiento, no consumir alcohol ni otras drogas, y respetar la normativa del centro cuando se encuentran en él, siempre bajo la amenaza de ser regresados a segundo grado si no cumplen con lo establecido en su programa (ampliamente, Martí 2019b).

Además, la literatura criminológica muestra que las prisiones abiertas presentan sus propias penalidades y que una parte importante de las personas presas que cumplen condena en ellas, a pesar de valorar positivamente algunos aspectos de la semilibertad, siguen

\footnotetext{
${ }^{44}$ Adicionalmente, se ha demostrado que la reincidencia de los clasificados inicialmente en tercer grado es mínima. En un estudio entre los penados de los centros de Cataluña que accedieron de esta forma al tercer grado, el 83\% no había reincidido cinco años después (Cutiño, 2013, p. 275). Ciertamente podría alegarse que un centro ordinario o cerrado tiene un mayor efecto preventivo general o preventivo especial negativo (incapacitación) que un centro abierto. No obstante, ni la incapacitación ni la finalidad de ocasionar un mayor temor acostumbran a ser en la actualidad consideradas el único fundamento de la pena.

${ }^{45}$ Esta cuestión no se ha discutido específicamente en el caso de las condenas cortas, sino desde una perspectiva más general (véase, por ejemplo, Manzanares, 2014 o Mata, 2015).
}

Revista Española de Investigación Criminológica

Artículo 4, Número 18 (2020)

https://doi.org/10.46381/reic.v18i0.387

www.criminologia.net

ISSN: 1696-9219 
experimentando y describiendo su situación como si estuvieran en una cárcel (Martí, 2018; Shammas, 2014).

El segundo argumento en contra de que las condenas cortas accedan directamente al régimen abierto apunta a que tener una condena corta no siempre es sinónimo de tener un "perfil de tercer grado". De acuerdo con algunos profesionales del sistema penitenciario catalán ${ }^{46}$ entrevistados por una de las autoras (Martí, 2018), aunque una persona haya sido condenada a una pena de, por ejemplo, seis meses de prisión, esta puede presentar "múltiples déficits" que desaconsejen su acceso al medio abierto (véase también CEJFE, 2014). Así, se repite en numerosas ocasiones la idea de que "aun cuando la pena es corta, los déficits de la persona son muchos", lo que desaconseja su acceso al régimen abierto.

De este modo, los "déficits" de la persona parecen tener un peso determinante en la posibilidad de ser clasificado en tercer grado en Cataluña y son utilizados como un argumento en contra de la clasificación inicial automática.

"Pueden venir condenas cortas por violencia de género con necesidades de intervención importantes y tener 5 meses. Más que la duración de la condena, lo importante es la valoración del riesgo. En general coincide con las condenas cortas, pero pueden ser condenas cortas y necesitar mucha intervención". Fragmento de una entrevista a una psicóloga de un centro abierto de Cataluña (Martí, 2018)

“[...]Tampoco la posibilidad de que las condenas cortas sean automáticamente iniciales, porque ha de depender de las características y necesidades de cada interno. El éxito del régimen abierto es que los internos sean realmente de régimen abierto, por las condiciones, no por la pena". Fragmento de una entrevista al director de un centro abierto de Cataluña (Martí, 2018)

A nuestro juicio, aun cuando la rehabilitación se conciba en términos de intervención basada en el tratamiento, debería insistirse en que no hay ningún motivo por el cual este no pueda suministrarse en el exterior. Nuestra propuesta de clasificar inicialmente en régimen abierto es todavía más defendible si la rehabilitación es entendida en términos de facilitar la reinserción. Precisamente, esta forma de cumplimiento de la pena no deteriora los lazos sociales de la forma tan drástica como sí lo hace la entrada en una prisión cerrada. Además, según la percepción de las propias personas presas, hay tres aspectos que se valoran

\footnotetext{
${ }^{46}$ Las opiniones de los profesionales que se exponen en este artículo son relativas al sistema penitenciario catalán (sin ser necesariamente representativos del mismo). Estas opiniones pueden diferir significativamente en el ámbito de la AGE, debido a las diferencias que caracterizan las prisiones abiertas de Cataluña y de la AGE (véase Martí, 2019a).
}

Revista Española de Investigación Criminológica

Artículo 4, Número 18 (2020)

https://doi.org/10.46381/reic.v18i0.387

www.criminologia.net

ISSN: 1696-9219 
positivamente de las prisiones abiertas en comparación con las cerradas: permiten a la persona tener un mayor contacto con su familia y su entorno, posibilitan "empezar de nuevo" sin la interrupción temporal o pérdida de tiempo que conlleva la prisión cerrada, y finalmente la pena se cumple en un entorno más humano, con una mayor "calidad de vida" que la existente en una prisión cerrada (Martí, 2018).

En el centro del debate sobre si las condenas cortas y por delitos menos graves deben ser clasificadas inicialmente en tercer grado reside la cuestión de si el acceso al régimen abierto debe decidirse fundamentalmente con base en principios de proporcionalidad o de rehabilitación. Defender que personas con penas cortas y "necesidades" varias deben ir a un régimen "ordinario" (a cumplir en prisión cerrada) implica aumentar la carga punitiva del castigo por las problemáticas sociales (von Hirsch \& Ashworth, 2005). Así, determinados colectivos ven sistemáticamente limitado el acceso al medio abierto al presentar mayores "variables de riesgo" o "déficits" (Cutiño, 2015c).

Sin duda, la falta de apoyo familiar, el consumo de drogas y el bajo nivel de recursos económicos deben ser valorados y ser objeto de intervención si se considera necesario. Lo que cuestionamos es que deban ser el fundamento que justifique la reclusión en una prisión cerrada, y que estas necesidades no puedan ser abordadas en régimen abierto.

En consecuencia, las prisiones abiertas deberían ser, en nuestra opinión, el destino principal de las condenas inferiores a 5 años sobre las cuales se ha acordado su ingreso en prisión, por tres razones principales: en primer lugar, las prisiones abiertas permiten que la persona siga teniendo un contacto diario con la comunidad, reduciendo la ruptura de vínculos sociales que conlleva el encarcelamiento en prisiones cerradas; en segundo lugar, las prisiones abiertas tienen capacidad para adaptar la intensidad y el contenido de la supervisión de las personas presas en función de cada caso; y en tercer lugar, porque la tesis de que los presos con ciertas problemáticas deben ser clasificados en segundo grado, a pesar de tener condenas cortas de prisión, penaliza a ciertos colectivos que presentan sistemáticamente más necesidades sociales y "variables de riesgo" (Martí, 2018).

Cabe destacar que aumentar el número de presos en régimen abierto sin que estos tengan "un perfil de tercer grado" puede aumentar el número de regresiones. Huelga decir

\section{Revista Española de Investigación Criminológica}

Artículo 4, Número 18 (2020)

https://doi.org/10.46381/reic.v18i0.387

www.criminologia.net

ISSN: 1696-9219 
que los recursos ahorrados en el régimen ordinario que supondría la aplicación de la propuesta realizada deberían destinarse a mejorar la intervención en el régimen abierto. Ello implica acompañar la clasificación inicial con otras medidas que refuercen el cumplimiento de la pena en semilibertad. La elaboración de un programa específico para personas en régimen abierto que requieren una supervisión más intensa o la ampliación de programas de deshabituación a las drogas en el medio abierto (por ejemplo, mediante el refuerzo de las comunidades terapéuticas) son modelos de posibles medidas ${ }^{47}$.

\subsection{La clasificación en los centros abiertos}

Una segunda propuesta alternativa consiste en prever un procedimiento de clasificación en las prisiones abiertas, esto es, en los CIS y los centros abiertos ${ }^{48}$. Como sabemos, en la actualidad, la práctica es que las personas condenadas estén en régimen "ordinario" (en prisión cerrada) mientras esperan la clasificación. Nuestra sugerencia es discutir la conveniencia de que la persona ingrese directamente en un CIS o centro abierto y esta primera propuesta de clasificación se realice desde allí, y no en una prisión cerrada como sucede actualmente. Este planteamiento se apoya en dos razones.

En primer lugar, el hecho de que los equipos técnicos y las Juntas de Tratamiento de los centros abiertos y CIS estén especializados en la ejecución de la pena en el medio abierto podría fomentar una mayor clasificación en tercer grado y un incremento del régimen abierto. Investigaciones anteriores muestran que los equipos técnicos y las Juntas de Tratamiento de algunas prisiones cerradas -las encargadas de realizar las propuestas de clasificación a tercer grado en la actualidad - tienen cierto desconocimiento y desconfianza hacia el trabajo que se

\footnotetext{
${ }^{47}$ Por ejemplo, Ibàñez (2019), que analiza los obstáculos para acceder al régimen abierto, destaca que algunos profesionales del sistema penitenciario consideran que los recursos comunitarios son escasos, tienen poca capacidad de absorción o no encajan fácilmente con los perfiles de internos que salen desde el régimen ordinario.

${ }^{48}$ CEJFE (2014, p. 245) aboga por un "sistema de clasificación exprés" para las condenas más cortas (sin especificar el tipo de centro).
}

Revista Española de Investigación Criminológica

Artículo 4, Número 18 (2020)

https://doi.org/10.46381/reic.v18i0.387

www.criminologia.net

ISSN: $1696-9219$ 
realiza en el régimen abierto $^{49}$, reticencias que es de suponer desaparecerían si son los equipos de régimen abierto los encargados de clasificar.

En segundo lugar, si el proceso de clasificación se realizara en los CIS y centros abiertos, en los casos en los que se decidiera clasificar en tercer grado ya no sería necesario efectuar el traslado de la persona desde una prisión cerrada. Ello permitiría que el proceso fuera más corto ${ }^{50}$ porque cuando la clasificación se lleva a cabo en las prisiones cerradas, la evaluación inicial la realiza el equipo de la prisión cerrada y, si se acuerda el tercer grado de una persona, esta debe ser trasladada a un centro abierto y evaluada de nuevo por el equipo técnico de este centro para ajustar el programa de tratamiento. Con nuestra propuesta, además, la persona podría empezar antes sus actividades en semilibertad, porque el equipo técnico evaluador -el que realiza la primera clasificación- sería el mismo que el que tiene que diseñar el programa de tratamiento en régimen abierto (es decir, el equipo técnico y la Junta de Tratamiento del centro abierto).

No obstante, la idea de realizar las clasificaciones en los centros abiertos tampoco acaba de recibirse de manera positiva por parte de algunos profesionales del sistema penitenciario catalán. Este nuevo sistema, se defiende, obligaría a los centros abiertos -que en Cataluña solo tienen presos con modalidades de vida plenas que pasan la mayor parte del día en el exterior- a disponer de medidas de seguridad adicionales para custodiar a estas personas. Al respecto, algunos profesionales consideran que estas medidas no son propias a la naturaleza de la prisión abierta y su adopción conllevaría dejar de tener un modelo de régimen abierto “puro” (Martí, 2018).

"La posibilidad de hacer la primera propuesta de clasificación desde los centros abiertos dificulta el modelo funcional de los centros abiertos, porque necesitaría más compuertas, más seguridad, porque, claro, de mientras estarían en régimen ordinario. Es decir, un espacio de régimen ordinario dentro del mismo centro abierto... No sería un régimen abierto puro. Si se da vía libre a esta posibilidad, se está diciendo que eres un centro abierto, pero con capacidad de centro ordinario y creo que no debemos mezclar las cosas, que debe preservarse el régimen

\footnotetext{
${ }^{49}$ Véase también nota 38.

${ }^{50}$ Cabe destacar que el tiempo que transcurre entre el ingreso en prisión y el acceso efectivo a la semilibertad, según Capdevila et al. (2005, p. 74), es un promedio de 121,44 días. Es decir, incluso las personas que son clasificadas inicialmente en tercer grado pasan los primeros cuatro meses en una prisión cerrada antes de que se materialice el acceso al régimen abierto.
}

Revista Española de Investigación Criminológica

Artículo 4, Número 18 (2020)

https://doi.org/10.46381/reic.v18i0.387

www.criminologia.net

ISSN: 1696-9219 
abierto sin matices de régimen ordinario". Fragmento de una entrevista al director de un centro abierto de Cataluña (Martí, 2018)

Es cierto que la posibilidad de que todas las clasificaciones se realicen en los centros abiertos conlleva varias implicaciones prácticas para el funcionamiento de estos. Al respecto, podría discutirse la conveniencia de que los centros abiertos, como sucede en los países escandinavos, tengan "secciones semi-cerradas". Así, es conocido que los países del norte de Europa hacen un extenso uso de las denominadas open prisons, llegando a albergar porcentajes de hasta el $60 \%$ de la población penitenciaria, lo cual previsiblemente es posible debido a esta mayor flexibilidad de sus prisiones abiertas (Martí, 2019c).

No obstante, el régimen abierto de las prisiones nórdicas no siempre se traduce en salidas diarias de los presos (como es el caso de Cataluña), sino que se refiere a una flexibilización de las condiciones dentro de las prisiones. Así, los presos en prisiones abiertas en Dinamarca o Noruega tienen amplia autonomía dentro del perímetro de la cárcel y considerables oportunidades para trabajar y realizar actividades, y también tienen mayor acceso a permisos de salida, pero solo unos pocos pueden salir a trabajar en la comunidad durante el día. Por este motivo, existen ciertas dudas acerca de si este tipo de prisiones, donde las personas siguen confinadas, aunque dentro de un perímetro "más amplio", pueden calificarse como “abiertas” (véase la discusión en Martí, 2019c).

De este modo, el peligro de admitir la existencia de "secciones semi-cerradas" en un centro abierto para facilitar la clasificación o para promover el cumplimiento de las penas cortas en semilibertad es que podría eventualmente desnaturalizar las características de lo que hoy entendemos por un "centro abierto". Precisamente esto es lo que sucede en los CIS en el ámbito de la AGE, los cuales permiten tener presos en tercer grado con modalidades de semilibertad restringidas (por ejemplo, que solo salen los fines de semana). En concreto, el $72,4 \%$ de las personas que están en un CIS en la AGE tienen una modalidad de semilibertad restringida (Martí 2019a, p. 231). El porcentaje es tan elevado que en realidad lo que se está produciendo es un fraude de etiquetas (véase también Cutiño, 2015b), pues, si bien están en un "centro abierto", de facto cumplen la pena en régimen ordinario. 
En todo caso, a nuestro juicio, la clasificación inicial en los centros abiertos conllevaría una mayor aplicación del régimen abierto, y la existencia de "secciones semicerradas", que debería ser excepcional y restrictiva, debería ser solo una forma de facilitar las clasificaciones. En últimas, para evitar los riesgos de "fraude de etiquetas", los centros abiertos deberían ser también objeto de análisis criminológico continuo.

\section{Conclusiones}

En España solo el 16,8\% de las personas presas están clasificadas en tercer grado, mientras que el restante $83,2 \%$ se encuentran en prisiones cerradas -ya sea clasificadas en primer grado $(1,9 \%)$, en segundo grado $(74,4 \%)$ o en espera de clasificación $(6,9 \%)$. Entendemos que el régimen abierto es susceptible de ser ampliado por políticas penitenciarias, lo cual se deduce de comparar las cifras de la AGE con las de Cataluña: mientras en la primera el porcentaje de personas presas en tercer grado a diciembre de 2019 es del 15,6\%, en la segunda alcanza el $24,5 \%$.

A pesar de que la clasificación penitenciaria se presume basada en un juicio individualizado, o en el estudio de variables penales, cuesta no llegar a la conclusión de que todo el sistema opera bajo un cierto automatismo en el que la costumbre y "por defecto" llevan a la inmensa mayoría de los condenados a ser clasificados en régimen ordinario y cumplir su pena en una prisión cerrada.

En este trabajo, hemos constatado que, solo el 34\% de las personas en régimen abierto accedieron al mismo desde el inicio de la condena y hemos analizado que la duración de la condena es un aspecto clave que influye en las posibilidades de acceder al tercer grado de forma inicial. A pesar de que las condenas cortas acceden al tercer grado inicial en mayor proporción que las condenas largas, hemos comprobado que el 49,3\% de las penas inferiores a 2 años y el 71,9\% de las penas de 2 a 5 años clasificadas por primera vez en 2019 en Cataluña recibieron el segundo grado como clasificación inicial. De esta forma, hemos concluido que incluso las condenas más cortas a menudo reciben una clasificación inicial en un régimen "ordinario" (que se cumple en una prisión cerrada), cuando sería defendible que,

\section{Revista Española de Investigación Criminológica}


atendiendo a su poca gravedad, estas penas pudieran cumplirse desde el inicio en régimen abierto.

En el caso de las condenas cortas, no clasificarlas inicialmente en tercer grado es aún más criticable ya que una parte importante de ellas finalizan habiendo cumplido la totalidad de la condena en una prisión cerrada, ya sea porque no han llegado a ser clasificadas, generalmente por falta de tiempo, o porque tienen mayores dificultades para progresar al tercer grado que las condenas más largas cuando han sido previamente clasificadas en segundo grado. Así, con datos de Cataluña, sabemos que el 74\% de las penas inferiores a 2 años $^{51}$ y el 43,2\% de las penas de entre 2 y 5 años que finalizaron en 2010 extinguieron la condena estando en una prisión cerrada, esto es, sin progresar al tercer grado y carecieron por tanto de una transición escalonada a la comunidad ${ }^{52}$.

Por otra parte, con respecto al acceso a régimen abierto por progresión, hemos constatado que el 66\% de las personas que accedieron al tercer grado en 2018 en España lo hicieron mediante progresión de grado. Por ello hemos examinado los criterios requeridos por la Administración penitenciaria, advirtiendo que la valoración de la progresión de grado no solo tiene en cuenta la duración de la condena, sino que toma en consideración otras variables de tipo socioeconómico, entre las cuales se encuentra no tener un domicilio o no ser acogido por una institución, y no tener oportunidades claras de trabajo fuera de prisión ${ }^{53}$. Estas exigencias excluyen a un sector importante de la población condenada y representan un mayor castigo por la exclusión social, siendo lo que explica en algunos casos su clasificación en un régimen “ordinario” (que se cumple en una prisión cerrada).

${ }^{51}$ El 38,1\% no habían sido clasificadas y el 35,8\% estaban clasificadas en primer o segundo grado.

${ }^{52}$ Cabe la posibilidad de que algunas de estas personas hubieran sido clasificadas en tercer grado y hubieran sufrido una regresión. Según el estudio de Cid \& Tébar (2013, p. 69) un 40,4\% de la población regresada no vuelva a recuperar los permisos, lo que llevará normalmente a finalizar la condena en segundo grado; y del $59,6 \%$ de personas que obtienen permisos después de la regresión, un 36\% no llega a conseguir el tercer grado o la libertad condicional.

${ }^{53}$ De modo que accederían más fácilmente a la semilibertad “aquellos delincuentes ocasionales, la delincuencia de cuello blanco o la que proviene de la clase media que no requieren programas específicos de tratamiento y probablemente no recaerán en el delito si mantienen sus condiciones de vida" (Cutiño, 2015b, p. 65). Para Cutiño (2015b, p. 65), esta situación es discriminatoria, pues la forma de cumplimiento en régimen abierto es tan diferente de la prisión cerrada "que casi podríamos hablar de penas distintas". 
Frente a esta situación, hemos defendido dos propuestas dirigidas a incentivar la clasificación inicial en tercer grado de las condenas cortas. La primera consiste en clasificar en tercer grado de forma inicial automática a las condenas inferiores a 5 años, por tres razones principales: en primer lugar, las prisiones abiertas permiten que la persona siga teniendo un contacto diario con la comunidad, reduciendo la ruptura de vínculos sociales que conlleva el encarcelamiento en prisiones cerradas; en segundo lugar, las prisiones abiertas tienen capacidad para adaptar la intensidad y el contenido de la supervisión de las personas presas en función de cada caso; y en tercer lugar, porque la tesis de que los presos con ciertas problemáticas deben ser clasificados en segundo grado, a pesar de tener condenas cortas de prisión, penaliza a ciertos colectivos que presentan sistemáticamente más necesidades sociales y "variables de riesgo" (Martí, 2018).

La segunda propuesta alternativa es que el procedimiento de clasificación se realice en los centros abiertos o CIS. En nuestra opinión el hecho de que los equipos técnicos y las Juntas de Tratamiento de los centros abiertos y CIS estén especializados en la ejecución de la pena en el medio abierto podría fomentar una mayor clasificación de personas condenadas en tercer grado y promover el cumplimiento en régimen abierto.

Priorizar el cumplimiento de la pena en instituciones abiertas es aconsejable, considerando además que gran parte de los problemas que deben tratarse en régimen abierto surgen precisamente de haber estado en una prisión cerrada. Ello sucede en el caso de las condenas largas (las cuales implican graves problemas de prisionización), y también en las condenas más cortas, pues unos meses encerrado en una cárcel son suficientes para perder el trabajo, no poder pagar el alquiler o perder una pareja.

Disminuir el número de entradas en prisiones cerradas también puede ser positivo en términos económicos, y estos recursos podrían utilizarse para reforzar y mejorar la ejecución del régimen abierto y las condiciones de las prisiones abiertas. Así, por ejemplo, la creación de un programa en medio abierto específico para presos que requieran una supervisión inicial más intensa podría ser una opción para asegurar que ciertas necesidades pueden ser abordadas 
en semilibertad, y evitar así que perfiles considerados como más problemáticos sean clasificados en segundo grado ${ }^{54}$.

Para finalizar, queremos enfatizar que nuestras dos propuestas se realizan teniendo en cuenta el marco penal y penitenciario actual, y se refieren a aquellos casos sobre los cuales ya se ha acordado el ingreso en prisión. Es evidente que no estamos defendiendo que el cumplimiento de la pena en prisiones abiertas deba ser la primera respuesta del sistema penal a las condenas cortas de prisión. A la inversa, lo que proponemos es que el régimen “ordinario", que se cumple en una prisión cerrada, sea también la ultima ratio respecto de las condenas a penas de prisión.

\footnotetext{
${ }^{54} \mathrm{La}$ adopción de cualquiera de las propuestas sugeridas requiere necesariamente dotar de mayores recursos humanos, tratamentales y económicos a las prisiones abiertas y al resto de instituciones de régimen abierto.
} 


\section{Referencias}

Capdevila, Manel, Ramon Parés, Marta Ferrer, Eulàlia Luque \& $\mathrm{M}^{\mathrm{a}}$ del Mar Torrecillas. (2005). La clasificación inicial en régimen abierto de los condenados a prisión. Barcelona: Centre d'Estudis Jurídics i Formació Especialitzada.

CEJFE. (2014). La libertad condicional en Cataluña. Barcelona: Centre d'Estudis Jurídics i Formació Especialitzada.

CEJFE. (2015). Tasa de reincidencia penitenciaria 2014. Barcelona: Centre d'Estudis Jurídics i Formació Especialitzada

Cervelló, Vicenta. (2005). La clasificación en tercer grado como instrumento de resocialización. Estudios de Derecho Judicial, 84, 157-204.

Cervelló, Vicenta. (2012). Derecho penitenciario. $3^{\mathrm{a}}$ ed. Valencia: Tirant lo Blanch.

Cid, José \& Beatriz Tébar. (2013). Regresión a segundo grado: causas y consecuencias. Barcelona: Centre d’Estudis Jurídics i Formació Especialitzada.

Cutiño, Salvador. (2013). Sobre el fin de la pena de prisión. Análisis del principio de resocialización y su realidad en el sistema español. Tesis doctoral. Departamento de Derecho Público, Universidad Pablo de Olavide de Sevilla.

Cutiño, Salvador. (2015a). Algunos datos sobre la realidad del tratamiento en las prisiones españolas. Revista Electrónica de Ciencia Penal y Criminología, 17(11), 1-41.

Cutiño, Salvador. (2015b). Clasificación en tercer grado y régimen abierto en el sistema penitenciario español. Revista Penal, 36 (Julio), 61-84.

Cutiño, Salvador. (2015c). La clasificación en grados. Análisis crítico de la normativa penitenciaria. Revista de Derecho y Proceso Penal, 38 Abril-Junio, 201-239.

Faraldo, Patricia. (2014). Luces y sombras del papel atribuido a los intereses patrimoniales de la víctima durante la ejecución de condenas por terrorismo, Oñati socio-legal series, 4(3), 443-464.

Fernández Arévalo, Luis \& Javier Nistal. (2012). Manual de derecho penitenciario. $2^{\mathrm{a}}$ ed. Cizur Menor: Aranzadi.

Fuentes, Juan Luis. (2011). Sistema de clasificación penitenciaria y el 'periodo de seguridad' del art. 36.2 CP. Indret: Revista para el Análisis del Derecho, 1, 1-28.

Gallego, Manuel, Pedro José Cabrera, Julián Carlos Ríos \& José Luis Segovia. (2010). Andar $1 \mathrm{~km}$ en línea recta. La cárcel del siglo XXI que vive el preso. Madrid: Universidad Pontificia Comillas.

García Mateos, Purificación. (2003). Régimen abierto y tercer grado: la lenta agonía de una esperanza. Dossier sobre la contrarreforma penal, 6, 110-115.

García Valdés, Carlos. (1989). Derecho Penitenciario (Escritos, 1982-1989). Madrid: Centro de Publicaciones del Ministerio de Justicia.

Revista Española de Investigación Criminológica

Artículo 4, Número 18 (2020)

https://doi.org/10.46381/reic.v18i0.387

www.criminologia.net

ISSN: 1696-9219 
Garro, Enara. (2017). Tercer grado y libertad condicional de condenados por delitos de terrorismo: una mirada desde la libertad ideológica y el derecho a no incriminarse. La gestión penitenciaria del final de ETA. Revista General de Derecho Penal, 28, 1-64.

Ibàñez, Aina \& José Cid. (2016). La reinserción de las personas que finalizan la condena en régimen ordinario. Barcelona: Centre d'Estudis Jurídics i Formació Especialitzada.

Ibàñez, Aina. (2019). Progresar hacia el régimen abierto: la visión de los profesionales. Revista Española de Investigación Criminológica, 7(17), 1-28.

Juanatey, Carmen. (2016). Manual de Derecho Penitenciario. 3a. Madrid: Iustel.

Larrauri, Elena. (2019). 'Se inventan sus leyes' ¿Qué criterios se deben valorar en la concesión de permisos penitenciarios?, Jueces para la Democracia, 94, 43-59.

Larrauri, Elena. (2020). Reducing Discretion in the Administration of Prison Leave, en Search of Legitimacy. European Journal on Criminal Policy and Research, 1-16. doi: 10.1007/s10610-019-09435-1

Landa, Jon. (2017). Fines de la pena en fase de ejecución penitenciaria: reflexiones a la luz de la prisión permanente revisable. Revista de derecho penal y criminología, 18, 91140.

Leganés, Santiago. (2013). La prisión abierta: nuevo régimen jurídico. Madrid: Edisofer.

López-Fonseca, Óscar. (2020, 18 de marzo). Interior facilita que los reclusos en semilibertad cumplan su condena en casa por el coronavirus, El País. Recuperado de: https://elpais.com/espana/2020-03-18/interior-facilita-que-los-reclusos-ensemilibertad-cumplan-su-condena-en-casa.html

López i Ferrer, Marayka. (2004). Cárceles abiertas. Tesis Doctoral. Departamento de Derecho, Universidad Autónoma de Barcelona, Bellaterra.

Manzanares, José Luis. (2014). Presente y futuro del sistema penitenciario de individualización científica. La Ley Penal: revista de derecho penal, procesal y penitenciario, 108 (Mayo-Junio), 1-14.

Martí, Marta. (2018). Un pie en la calle y otro en prisión: El cumplimiento de la pena en semilibertad en prisiones abiertas. Tesis Doctoral. Departamento de Derecho, Universitat Pompeu Fabra.

Martí, Marta. (2019a). La ejecución del régimen penitenciario abierto. Cuadernos de Política Criminal, Segunda Época, 127, 203-236.

Martí, Marta. (2019b). Prisiones abiertas: la supervisión de la pena de prisión en semilibertad. Revista Electrónica de Ciencia Penal y Criminología, 21(07), 1-26.

Martí, Marta. (2019c). Prisoners in the community: the open prison model in Catalonia. Nordisk Tidsskrift for Kriminalvidenskab, 2, 211-231.

Revista Española de Investigación Criminológica

Artículo 4, Número 18 (2020)

https://doi.org/10.46381/reic.v18i0.387

www.criminologia.net

ISSN: $1696-9219$ 
Mata, Ricardo. (2015). Clasificación penitenciaria y régimen abierto. En Derecho Penitenciario. Enseñanza y aprendizaje, editado por R. De Vicente, 152-178. Valencia: Tirant lo Blanch.

Pedrosa, Albert. (2019). ¿A quién dejamos atrás? Explorando los obstáculos de la progresión penitenciaria. Revista Electrónica de Investigación Criminológica, 2(17), 1-24.

Peñaranda, Enrique. (2019). La pena: nociones generales, en Introducción al Derecho Penal, editado por Bacigalupo, S., Lascuraín, J. A. (coord.) \& Rodríguez (pr.). Thomson Reuters-Civitas.

Ríos, Julián C. \& Pedro J. Cabrera. (1998). Mil voces presas. Comillas: Universidad Pontificia de Comillas.

Ríos, Julián C. \& Pedro J. Cabrera. (2002). Mirando el abismo. El régimen cerrado. Comillas: Universidad Pontificia Comillas.

Rovira, Martí, Elena Larrauri \& Pau Alarcón. (2018). La concesión de permisos penitenciario. Revista Electrónica de Ciencia Penal y Criminología, 20(2), 1-26.

Secretaría General de Instituciones Penitenciarias (SGIP). (2019). Informe anual del 2018. Ministerio del Interior - Secretaría General Técnica.

Shammas, Victor L. (2014). The pains of freedom: Assessing the ambiguity of Scandinavian penal exceptionalism on Norway's Prison Island. Punishment \& Society, 16 (1), 10423. https://doi.org/10.1177/1462474513504799

SMPRAV [DGSP]. (2011). El model de rehabilitació a les presons catalanes. Secretaría de Mesures Penals i Reparació i Atenció a la Víctima, Departament de Justícia. Disponible en: http://justicia.gencat.cat/web/.content/documents/publicacions/model_rehabilitacio presons catalanes.pdf

Solar, Ma del Puerto. (2009). Consecuencias de la Ley Orgánica 7/2003 en el ámbito penitenciario. Diario La Ley, 7238, 1-11.

Solar, Ma del Puerto. (2018). El sistema penitenciario en la encrucijada: Estado actual y propuestas de futuro tras las últimas reformas penales. Por un papel activo de los Juristas de II.PP. Tesis Doctoral. Universidad Autónoma de Madrid, Madrid.

Torrecilla, María del Prado. (2009). Balance de la LOGP tras treinta años de vigencia. Necesidad de abordar algunas reformas. Diario la Ley, 7250, 1-2.

Varona, Daniel. (2019). La suspensión de la pena de prisión: razones de una historia de éxito. Revista Española de Investigación Criminológica, 17, 1-35.

Von Hirsch, Andrew \& Andrew Ashworth. (2005). Proportionate sentencing: exploring the principles. Oxford: Oxford University Press. https://doi.org/10.1093/acprof:oso/9780199272600.001.0001 


\section{Financiamiento}

Este estudio se inscribe en el proyecto "Ejecución y supervisión de la pena: Calidad de la intervención, legitimidad y reincidencia» financiado por MINECO (Ref. DER2015-64403P), FEDER, UE; también en el marco de las Ayudas a las acciones de dinamización "Redes de Excelencia" proyecto: Desarrollo de un modelo criminológico y empírico de la política criminal - Acrónimo EmpiriC -. Financiado por MCIU-AEI (Ref. DER2017-90552-REDT).

Marta Martí es Doctora en derecho (criminología) por la Universitat Pompeu Fabra. Actualmente es profesora colaboradora de la Universitat Oberta de Catalunya y consultora de investigación en criminología. Sus temas de interés son el sistema de penas, las prisiones y la violencia de género.

https://orcid.org/0000-0001-6666-9039

Elena Larrauri es Catedrática de derecho penal y criminología en la Universitat Pompeu Fabra. Actualmente es la investigadora principal de la Red de Excelencia EmpriC. Sus líneas de investigación son el sistema penitenciario, los antecedentes penales, el sistema de penas y el análisis de género en el sistema de justicia penal.

https://orcid.org/0000-0001-7556-3236 


\section{Anexos}

\section{Tabla I.}

\section{Criterios de acceso al tercer grado según la Instrucción SGIP 9/2007 (AGE)}

\section{Criterios generales}

- Existencia de alguna de las siguientes situaciones:

* Continuidad en el exterior en programas de tratamiento que ya venga realizando el interno

* Necesidad de tratamiento en medio comunitario

* Proyecto de vida sólido y contrastable para hacer una vida honrada en libertad

- Haber disfrutado de permisos penitenciarios puede orientar y favorecer la progresión pero no es requisito indispensable

\section{Criterios específicos ${ }^{55}$}

\section{Clasificaciones iniciales}

- Pronóstico de reincidencia de medio bajo a muy bajo

* Ingreso voluntario

* Condenas inferiores a 5 años

* Primariedad delictiva o reincidencia escasa

* Antigüedad en la causa por la que ingresó

* Correcta adaptación social desde la comisión de los hechos hasta el ingreso

* Baja prisionización

* Apoyo familiar pro social

* Asunción del delito

* Personalidad responsable

* En el caso de adicciones, que se halle en disposición de tratamiento

- No presentar factores de inadaptación

* Pertenencia a organizaciones delictivas

* Personalidad de rasgos de carácter psicopático

* Inadaptación a prisión

* Escalada delictiva, etc.

\section{Progresiones de grado}

- Evolución favorable en segundo grado de tratamiento, constatada por:

* Obtener una valoración normal o superior en las evaluaciones.

* Estar incluido en un programa de tratamiento que pueda continuar en el medio comunitario.

* Permisos disfrutados sin incidencias o internos que sin haber disfrutado de permisos, su evolución y fechas de cumplimiento aconsejan el tercer grado

* Ausencia de sanciones disciplinarias

* En delitos de extrema gravedad o que hayan provocado alarma social, se exige un estudio exhaustivo de las circunstancias y de los posibles tratamientos que deban seguir

Fuente: Elaboración propia a partir de la Instrucción SGIP 9/2007.

${ }^{55}$ Además, la SGIP 9/2007 establece una serie de variables a considerar para la aplicación de las distintas formas de ejecución abierta.

Revista Española de Investigación Criminológica

Artículo 4, Número 18 (2020)

https://doi.org/10.46381/reic.v18i0.387

www.criminologia.net

ISSN: 1696-9219 


\section{Tabla II.}

Características de las personas presas según si fueron clasificadas inicialmente en segundo o en tercer grado

\begin{tabular}{|c|c|c|}
\hline & $2^{\circ} \mathrm{g}$ & 3r grado inicial \\
\hline \multicolumn{3}{|c|}{ Variables individuales } \\
\hline Hombre & $90,6 \%$ & $93,4 \%$ \\
\hline Nacionalidad española* & $71,7 \%$ & $86,8 \%$ \\
\hline Toxicomanía en activo* & $59,3 \%$ & $35,5 \%$ \\
\hline Enfermedad física crónica* & $11,4 \%$ & $19 \%$ \\
\hline Problemática de salud mental & $18,6 \%$ & $14 \%$ \\
\hline \multicolumn{3}{|c|}{ Variables sociofamiliares } \\
\hline Tiene apoyo familiar* & $80 \%$ & $88,2 \%$ \\
\hline Tiene pareja* & $48,1 \%$ & $63,4 \%$ \\
\hline Tiene cargas familiares* & $46,3 \%$ & $54,7 \%$ \\
\hline La familia tiene antecedentes delictivos * & $46,3 \%$ & $27,3 \%$ \\
\hline La pareja tiene antecedentes delictivos* & $48,6 \%$ & $23,3 \%$ \\
\hline Tiene una vivienda estable* & $78,2 \%$ & $90,6 \%$ \\
\hline Tiene opción laboral ${ }^{* *}$ & $31,1 \%$ & $77,8 \%$ \\
\hline \multicolumn{3}{|c|}{ Variables penales y criminológicas } \\
\hline Tiene ingresos previos en prisión* & $67,1 \%$ & $45,6 \%$ \\
\hline Primario en el delito* & $41,9 \%$ & $56,4 \%$ \\
\hline Causas pendientes* & $31,3 \%$ & $15,5 \%$ \\
\hline \multicolumn{3}{|l|}{ Tipo de delito* } \\
\hline Contra las personas & $11,3 \%$ & $10,2 \%$ \\
\hline Contra la libertad sexual & $9,8 \%$ & $0,7 \%$ \\
\hline Contra la propiedad & $31,4 \%$ & $39,2 \%$ \\
\hline Contra la salud pública & $36,8 \%$ & $31,1 \%$ \\
\hline Otros & $10,8 \%$ & $18,7 \%$ \\
\hline Delito violento & $22,5 \%$ & $17,7 \%$ \\
\hline \multicolumn{3}{|l|}{ Cuantía de la pena** } \\
\hline Hasta 6 meses & $4,9 \%$ & $22,6 \%$ \\
\hline 6 meses- 1 año & $9,5 \%$ & $17,2 \%$ \\
\hline 1-2 años & $9,2 \%$ & $10,9 \%$ \\
\hline 2-3 años & $12,1 \%$ & $22,2 \%$ \\
\hline 3-5 años & $23,2 \%$ & $23,8 \%$ \\
\hline 5-10 años & $28,4 \%$ & $3 \%$ \\
\hline 10-15 años & $7,8 \%$ & $0,3 \%$ \\
\hline más de 15 años & $4,9 \%$ & - \\
\hline Ha cumplido prisión preventiva* & $22,4 \%$ & $43,6 \%$ \\
\hline Ingresó de forma voluntaria* & $10,1 \%$ & $30,3 \%$ \\
\hline Ha cometido faltas disciplinarias & $62,5 \%$ & $10,5 \%$ \\
\hline Ha recibido sanciones & $59,9 \%$ & $8,9 \%$ \\
\hline
\end{tabular}

Fuente: Elaboración propia. Datos de Capdevila et al. (2005, pp. 59-70) 